\title{
Effects of Electronic Technology Antenatal Care (E-ANC) on Midwives and Pregnant Women during the COVID-19 Period
}

\author{
Rosmala Nur ${ }^{1 *}$, St. Radiah ${ }^{1}$, Ulfa Aulia ${ }^{1}$, Rahma Dwilarasati ${ }^{1}$, Nurhaya S. Patui ${ }^{1}$, Elvaria Mantao ${ }^{1}$, Syaiful Hendra $^{2}$, \\ Hajra Rasmita Ngemba ${ }^{2}$, Muh Rusydi ${ }^{3}$, Nenita P. Dominggo ${ }^{4}$ \\ ${ }^{1}$ Department of Public Health, Faculty of Public Health, Tadulako University, Palu, Indonesia; ${ }^{2}$ Department of Information \\ Technology, Faculty of Engineering, Tadulako University, Palu, Indonesia; ${ }^{3}$ Department of Geophysics, Faculty of Mathematics \\ and Natural Sciences, Tadulako University, Palu, Indonesia; ${ }^{4}$ Department of Asian Languages and Cultures, California \\ University, California, United States
}

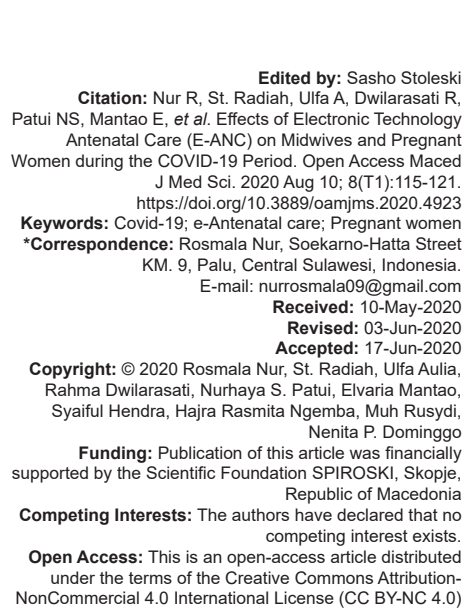

\section{Introduction}

The coronavirus disease 2019 (COVID-19) was first reported in Indonesia on March 2, 2020, with the country originally having two cases. However, data from May 9, 2020, reveal that it already has a total of 13,645 confirmed cases with 959 deaths. Furthermore, the mortality rate was estimated to be at $8.9 \%$. This is the highest in Southeast Asia, resulting from the ability to infect all people, including even pregnant, postpartum, and breastfeeding mothers [1]. This infective prospect instigates the high recommendation of prevention, as a means to minimize the virus exposure. The most common instruction for everyone include social distancing and staying at home [1], [2]. Furthermore, such condition affects the scope of antenatal care (ANC) visits. Based on the data obtained from the
Public Health Center of Tinggiede and Marawola during the lockdown period (March 10-April 10), there was a very low percentage $(0.1 \%)$ ANC visits. The same is true also for home check-ups by midwives, in cases of COVID-19-related complaints. These practices are known to be very important to monitor the pregnancy development of women, to detect possible abnormalities and complications early on Rasmussen et al. [3]. In addition, the provision of complete ANC promotes speedy and correct treatment, leading to a reduction in morbidity risks. Such may also reduce the possibility of death of the mother and child during the COVID-19 period [4].

These challenges facilitate the need to identify the alternative means of achieving proper ANC. Therefore, an Android-based electronic technology antenatal care (e-ANC), specifically designed for midwives and pregnant women, is expected to increase 
online ANC coverage for health counseling, high-risk early detection, $\mathrm{Hb}$ monitoring, and the provision of Fe tablets. This relatively new model improves the midwives' ability to monitor pregnancy development. Furthermore, it also aids in their capacity to provide services at any time and any place without physical contact. However, communication and education are needed for both parties to maximize e-ANC features. This is true, especially in obtaining information, counseling, and communicating with health workers [5]. The pregnant women tend to feel more comfortable through their pregnancy, childbirth, and puerperal within the COVID-19 period, subsequently assuring safe delivery and good health of their baby [6].

Research on mobile health technology (m-Health) using Android has been carried out by Haddad et al., Feroz et al. Schwartz [7], [8], [9]. However, the locus is currently limited to health workers, in conditions unaffected by the COVID-19 pandemic. A study on electronic technology involvement in the COVD-19 pandemic situation for midwives and pregnant women to improve maternal and infant health has never been conducted. This prompts the need to perform applied research on the effects of e-ANC for midwives and pregnant women during the pandemic, as a model for improving ANC. This study, therefore, aims to determine the effect of the COVID-19 pandemic on ANC visits. It also seeks to evaluate the effect of e-ANC on the participation of midwives and pregnant women in counseling, high-risk early detection, monitoring of $\mathrm{Hb}$ and $\mathrm{Fe}$ tablets, and the impact on their reproductive health.

The e-ANC model has many advantages. First, it provides intensive counseling to pregnant women and midwives regarding maternal and child health, with respect to the COVID-19 pandemic. Second, midwives are able to effectively monitor pregnant women, detect high-risk pregnancies early on, and evaluate $\mathrm{Hb}$ and $\mathrm{Fe}$ tablets and the development of pregnancy conditions without physical contact, anytime and anywhere. Third, the model is simple, easy to understand, and is cost effective during the pandemic.

\section{Materials and Methods}

\section{Research design, place, and sample}

This is quasi-experimental study that used preand post-tests. The study was conducted in 11 villages within the Public Health Center area of Tinggiede and Marawola, Sigi Regency, Central Sulawesi Province, from February 9, 2020, to May 9, 2020. Moreover, a purposive sampling technique was used to select 30 respondents, based on the inclusion criteria of pregnant women (in their second trimester [ $>4$ months], with willingness to participate, ability to speak Indonesian, and the ability to use an Android device). Meanwhile, 20 midwives were chosen as respondents (on duty at the Tinggiede and Marawola Public Health Center, and the ability to use an Android device).

\section{Data collection technique}

Before distributing the e-ANC application, secondary data were obtained from the midwives in the Tinggiede and Marawola Public Health Centers. However, secondary data were obtained from 11 more village midwives online. This information was related to the antenatal coverage before (February 9, 2020-March 9, 2020) and after the lockdown period (March 10, 2020-April 9, 2020). Moreover, midwife services during the pandemic, with regard to counseling, high-risk early detection, and $\mathrm{Hb}$ and Fe tablets monitoring were also considered. Data on the reproductive disorders experienced by pregnant women during the lockdown period were also obtained.

In addition, between April 9, 2020, and May 9, 2020, treatment was provided following the e-ANC application distribution. There was also a tutorial on usage of the application's treatment to both midwives and pregnant women. However, any barriers or issues recognized are asked and resolved online. The e-ANC is continuously developed every day based on the firsthand observations, with the help of midwife coordinators and Public Health Center heads. All the data from the respondents were analyzed on May 9, 2020. In addition, the e-ANC is made up of very simple content. These include, among others, a complete ANC, counseling, information on the need for high-risk early detection, $\mathrm{Hb}$ and Fe tablets monitoring, information on the danger of pregnancy, healthy living behavior during the pandemic, prevention methods, and the dangers and impact of the COVID-19 pandemic.

\section{Data analysis technique}

The differences were analyzed using paired sample t-tests.

\section{Results}

\section{Social demographic characteristics of respondent}

The respondents' characteristics were based on age, occupation, education, and number of children.

Based on Table 1, majority of the pregnant women were aged $20-35$ years $(56.7 \%)$, indicating that the average respondent was within the ideal childbearing age. Furthermore, $76.7 \%$ of the participants were 
housewives, hence, the absence of a steady income. On the other hand, $56.3 \%$ had a last education of senior high school, suggesting the participants' moderate capacity of using Android devices with the e-ANC feature. Moreover, the highest number of children was $>3(60 \%)$, showing the non-compliance with the National Family Planning Coordinating Agency recommendation of at most two children. Conversely, $60.0 \%$ of the midwives were aged 35-55 years, indicating the presence of a relatively young and productive workforce in both the Public Health Centers. In addition, $49.1 \%$ of the midwives have served for $\geq 5$ years, suggesting a relatively high experience level in providing ANC.

Table 1: Distribution of respondents based on their social demographics characteristics

\begin{tabular}{|c|c|c|}
\hline Characteristics & Frequency & Percentage \\
\hline \multicolumn{3}{|l|}{$\begin{array}{l}\text { Pregnant woman } \\
\text { Age }\end{array}$} \\
\hline$<20$ years old & 12 & 40.0 \\
\hline 20-35 years old & 17 & 56.7 \\
\hline$>35$ years old & 1 & 3.3 \\
\hline Total & 30 & 100 \\
\hline \multicolumn{3}{|l|}{ Occupation } \\
\hline Employee & 4 & 13.3 \\
\hline Entrepreneur & 3 & 10.0 \\
\hline Housewife & 23 & 76.7 \\
\hline Total & 30 & 100 \\
\hline \multicolumn{3}{|l|}{ Education } \\
\hline Elementary school & 7 & 23.3 \\
\hline Junior high school & 7 & 23.3 \\
\hline Senior high school< & 16 & 53.3 \\
\hline Total & 30 & 100 \\
\hline \multicolumn{3}{|l|}{ Number of children } \\
\hline$\geq 2$ & 14 & 40.0 \\
\hline$>3$ & 16 & 60.0 \\
\hline Total & 30 & 100 \\
\hline \multicolumn{3}{|l|}{ Midwife } \\
\hline \multicolumn{3}{|l|}{ Age } \\
\hline$<35$ years old & 1 & 5.0 \\
\hline $35-55$ years old & 12 & 60.0 \\
\hline$>55$ years old & 7 & 35.0 \\
\hline Total & 20 & 100 \\
\hline \multicolumn{3}{|l|}{ Length of work } \\
\hline$<5$ years & 7 & 35.0 \\
\hline$\geq 5$ years & 13 & 65.0 \\
\hline Total & 20 & 100 \\
\hline
\end{tabular}

\section{Effect of COVID-19 periods on ANC coverage of pregnant women}

Based on Table 2, the statistical test results showed an ANC coverage of 0.00 or $p<\alpha 0.05$. Thus, a significant difference is established between the outcome before (February 9, 2020-March 9, 2020) and after (March 10, 2020-April 9, 2020) the lockdown period.

Table 2: Difference in value of ANC coverage of pregnant women before and after the COVID-19 lockdown period

\begin{tabular}{llll}
\hline Variable & Mean & Standard deviation & p-value \\
\hline Before the COVID-19 lockdown period & -15.433 & 5.782 & 0.000 \\
After the COVID-19 lockdown period & & & \\
\hline
\end{tabular}

The effects of ANC on the improved midwife participation in counseling, high-risk early detection, $\mathrm{Hb}$ monitoring, and the provision of Fe tablets

Based on Table 3 , the statistical test results for counseling $p=0.00$ or $<\alpha 0.05$. Thus, a significant difference was established between the values reported before and after the intervention. Similarly, $p<0.00$ was recorded for high-risk early detection and $\mathrm{p}<0.002$ for examination of $\mathrm{Hb}$. Therefore, there was a significant difference between the values before and after the intervention. Furthermore, the provision of $\mathrm{Fe}$ tablets was at $p<0.003$, which confirms a significant discrepancy between the value estimated before and after the e-ANC.

Table 3: Difference in value of midwife participation in counseling, high-risk early detection, $\mathrm{Hb}$ examination, and provision of Fe tablets

\begin{tabular}{llll}
\hline Variable & Mean & Standard deviation & p-value \\
\hline $\begin{array}{l}\text { Counseling } \\
\text { Pre-intervention }\end{array}$ & -14.500 & 6.856 & 0.000 \\
$\begin{array}{l}\text { Post-intervention } \\
\text { High-risk early detection }\end{array}$ & & & \\
$\quad \begin{array}{l}\text { Pre-intervention } \\
\quad \text { Post-intervention }\end{array}$ & -17.950 & 4.718 & 0.000 \\
$\begin{array}{l}\text { Hb monitoring } \\
\quad \text { Pre-intervention }\end{array}$ & & & \\
$\quad \begin{array}{l}\text { Post-intervention } \\
\text { Provision of Fe tablets } \\
\quad \text { Pre-intervention } \\
\quad \text { Post-intervention }\end{array}$ & -15.550 & 4.617 & 0.002 \\
\hline
\end{tabular}

Effects of e-ANC on pregnant women for counseling, high-risk early detection, $\mathrm{Hb}$ examination, and provision of Fe tablets

Based on Table 4, the statistical test results for counseling showed $p=0.00$ or $<\alpha 0.05$. This shows that there were significant differences in pregnant women participation before and after the e-ANC intervention. Meanwhile, the high-risk early detection was at $p<0.00$, while the $\mathrm{Hb}$ examination was at $\mathrm{p}<0.002$. Such indicate significant differences in both parameters, similar for the provision of Fe tablets with $p<0.003$.

Table 4: Differences in the value of pregnant women participation in counseling, high-risk early detection, $\mathrm{Hb}$ examination, and provision of Fe tablets during the COVID-19 period

\begin{tabular}{|c|c|c|c|}
\hline Variable & Mean & Standard deviation & $\mathrm{p}$-value \\
\hline \multicolumn{4}{|l|}{ Counseling } \\
\hline $\begin{array}{l}\text { Pre-intervention } \\
\text { Post-intervention }\end{array}$ & -14.167 & 6.069 & 0.000 \\
\hline \multicolumn{4}{|c|}{ High-risk early detection } \\
\hline $\begin{array}{l}\text { Pre-intervention } \\
\text { Post-intervention }\end{array}$ & -18.900 & 4.318 & 0.000 \\
\hline \multicolumn{4}{|l|}{$\mathrm{Hb}$ monitoring } \\
\hline $\begin{array}{l}\text { Pre-intervention } \\
\text { Post-intervention }\end{array}$ & -14.833 & 5.045 & 0.002 \\
\hline \multicolumn{4}{|c|}{ Provision of Fe tablets } \\
\hline $\begin{array}{l}\text { Pre-intervention } \\
\text { Post-intervention }\end{array}$ & -15.400 & 3.701 & 0.003 \\
\hline
\end{tabular}

\section{Impact of disorders on women's reproductive health}

Table 5 shows the reproductive health problems suffered by pregnant women before the provision of ANC. These include dizziness or headache (46.6), fever $(10.0 \%)$, fetal death $(3.3 \%)$, miscarriage $(3.3 \%)$, and bleeding (10.0\%). Furthermore, $6.7 \%$ decline in dizziness and $3.3 \%$ decline in headache and fever were reported after the intervention. However, fetal death, 
miscarriage, and bleeding were all at $0.0 \%$. However, the incident of no complaints reached $90.0 \%$.

Table 5: Reproductive health problems pre- and postintervention during the COVID-19 period

\begin{tabular}{llllll}
\hline Reproductive health problems & \multicolumn{2}{l}{ Before } & & \multicolumn{2}{l}{ After } \\
\cline { 2 - 3 } & F & $\%$ & & $\%$ \\
\hline Dizziness/headache & 14 & 46.6 & & 2 & 6.7 \\
Fever & 3 & 10.0 & & 1 & 3.3 \\
Fetal death & 1 & 3.3 & & 0 & 0.0 \\
Miscarriage & 1 & 3.3 & & 0 & 0.0 \\
Bleeding & 3 & 10.0 & & 0 & 0.0 \\
Number of complaints & 22 & 73.4 & & 3 & 10 \\
No complaints & 8 & 26.6 & & 27 & 90.0 \\
Total & 30 & 100 & & 30 & 100 \\
\hline
\end{tabular}

\section{Discussion}

\section{Effect of the COVID-19 lockdown period on the ANC coverage for pregnant women}

The analysis showed a significant difference in the antenatal coverage before and after the COVID-19 lockdown period. This was the result of the Indonesian local governments recommending various safety measures against COVID-19 such as staying at home, working from home, social distancing, avoiding direct physical contact, and evading crowds [1], [2]. In addition, the disease has prevented pregnant women and health workers from visiting the Public Health Center, due to the fear of contracting the virus. This condition is congruent with Daw MA [10], where lockdown periods were reported to affect the visiting of pregnant women in health facilities. Meanwhile, midwives tend to perform more home visits on instances where there are complaints. The current study highlighted the service rendered at the Public Health Center to include only childbirth, and this is served according to the COVID-19 protocol [1].

\section{Effects of ANC application on increased} midwife participation in counseling, high-risk early detection, monitoring $\mathrm{HB}$, and provision of $\mathrm{Fe}$ tablets for pregnant women

The analysis showed a significant difference in the participation of midwives before and after using the e-ANC for counseling, detecting early high-risk pregnancies, measuring $\mathrm{Hb}$, and providing of Fe tablets to pregnant women (Table 3). This is possible because the application automatically modifies the midwives' behavior because communication, counseling, and evaluation are all conducted without direct physical contact with the pregnant women. The e-ANC feature allows for intense detailing about the pregnant women's health condition during the pandemic. Furthermore, there are also a number of questions from pregnant women relating to the ways of preventing, the harm caused, and the overall influence of the COVI-19. This further improves the midwives' knowledge [11], and counseling is now focused on the pregnancy and more on how it may be affected by COVID-19, thus subsequently impacting service improvement [2]. This situation indirectly promotes motivation and activity in providing ANC services [12], [13].

The study results are congruent with Segars et al., [14] where the midwives with knowledge on ANC and COVID-19 effectively conducted ANC according to COVID-19 standards. This expertise is also very useful for counseling, high-risk early detection, and improving overall maternal safety and infant health. In addition, the use of a risk approach in testing is important, especially in high-risk pregnancies [14], because the incidence of anemia ought to be detected very early [15], [16]. Therefore, it is mandatory for midwives to examine $\mathrm{Hb}$ and provide $\mathrm{Fe}$ tablets while providing ANC during the pandemic [17].

Based on the results, some midwives avoided reporting to the Public Health Centers for the fear of contracting the COVID-19 virus before the e-ANC implementation. This was because one of the criteria for identifying people under surveillance (ODP) includes people working and visiting health facilities involved with treating patients with COVID-19 symptoms [17]. Therefore, the use of e-ANC guarantees the feeling of safety, as services to pregnant women are now made possible without physically visiting the Public Health Center.

Furthermore, some midwives considered the tendency for $\mathrm{Hb}$ measurement to increase the duration of contact with pregnant women. However, e-ANC implementation increased the midwife participation in examination, as measurements were conducted at home and the health workers and pregnant women had to wear their personal protective equipment. The results obtained from the evaluation are used as a reference in explaining the benefits of iron tablets and the possible consequences of anemia [18]. This situation is in line with Yan et al. [19], where ANC enables the detection of problems faced by pregnant women in need of special services. These challenges include anemia, complications, high fever, and other symptoms with a tendency to endanger the lives of both the mother and child [20]. Therefore, the practice of early treatment saves pregnant women during the COVID-19 pandemic.

\section{Effects of ANC on pregnant women in counseling, high-risk early detection, $H B$ monitoring, and provision of Fe tablets}

The results showed that there were significant differences between counseling, high-risk early detection examinations, $\mathrm{Hb}$ monitoring, and provision of Fe tablets before and after the e-ANC intervention (Table 4). This occurred possibly because the implementation of the application influences the pregnant women's knowledge about pregnancy and COVID-19. Such is possible because the elements of e-ANC serve as guide for 
them in describing the actions to perform. Furthermore, the counseling benefits are obtainable at any time and any place without making physical contact with health workers. Moreover, pregnant women are able to personally detect their risk level (high or low). The results are also congruent with Haddad et al. and Feroz et al. [7], [8], where the use of information technology to serve pregnant women promotes the individuals' knowledge of the progress, because the results of previous examinations are reaccessible.

The most significant improvement after the e-ANC implementation is observed in the domain of counseling and high-risk early detection. Following the counseling instructions, four items were obtained to protect pregnant women against COVID-19. First, pregnant women must practice frequent handwashing with soap and running water for $20 \mathrm{~s}$ and use hand sanitizers with at least $70 \%$ alcohol content. Second, they must maintain a minimum distance of $1 \mathrm{~m}$ from other people and avoid crowded rooms. Third, they must avoid touching their eyes, nose, and mouth. Finally, they need to pay conscious attention to the cleanliness of their breathing, using a mask, especially when coughing or sneezing. In addition, the incidence of fever, cough, or difficulty in breathing requires contacting the nearest health worker or hospital immediately. The results of this study are in accordance with Ministry of Health of the Republic of Indonesia (1), where the COVID-19 protocol for pregnant women includes avoiding touching the eyes, nose, and mouth with unwashed hands, as well as avoiding physical contact with sick people. Furthermore, using a medical mask and staying at home when sick or visiting a suitable health facility immediately, keeping clean, and regularly disinfecting surfaces and frequently touched objects are effective preventive measures. In addition, Yan et al. and Lim et al. [20], [21], counseling about COVID-19 during pregnancy is very important to maintain the safety of pregnant women.

The e-ANC is an Android-based application, specifically designed for the COVID-19 pandemic. This application is used by pregnant women to personally detect their risk (high or low). Furthermore, health workers including doctors and midwives are able to monitor the development of pregnancy and the fetuses at any time. Clients feel safe and happy as services are provided at any time from home. This is congruent with the outcome of Haddad et al. Schwartz [7], [9], relating to the effect of health information technology on the quality of care provided to pregnant women during the pandemic. Furthermore, this is improved by health information technology, especially through reduced negligence in monitoring the pregnancy and fetus development [1], [7], [8].

\section{Impact of ANC on reproductive health problems during in the COVID-19 pandemic}

Reproductive health problems before and after the intervention decreased from $55.5 \%$ to
$3.6 \%$ (Table 5). This condition is possibly due to the integration of midwives and pregnant women on a single system, which ensured their regular and continuous communication and education. In addition, the presence of e-ANC improved counseling, high-risk early detection, monitoring $\mathrm{Hb}$ levels, and compliance in consuming $\mathrm{Fe}$ tablets during the pandemic. The midwives also now possess the knowledge and skills for early detection, needed to ensure timely resolution. This is in accordance with Ministry of Health of the Republic of Indonesia, Firdiiansyah, Saleh, [1], [22], [23], where the education model expected by pregnant women during in the COVID-19 pandemic is comprehensive for determining the pregnancy development.

Furthermore, other health problems, including fever, flu, and cough, similar to COVID-19 symptoms were very low (10\%) compared to the findings of Mamar et al., [6] where complaints in the form of fever/ convulsions, coughing, and spasms were reported by $55 \%$ of respondents. This is possible due to the stigma, stereotype, and subsequent marginalization assumed to worsen the health status and recovery rate of pregnant women, hence, the practice of concealing the information. In addition, there is fear of being ostracized by the community, and this greatly affects mental health (fear) and worsens the individuals' immunity. The research results are congruent with Firdiyansyah and Saleh [22], [23], where stigma and stereotyping contributed to the healing process of patients and high mortality rate resulting from the COVID-19 pandemic in Indonesia, for both the patient and the health workers. The issues of rejection of the COVID-19 corpse and patients by some communities prompt the reluctance to report the disease to health institutions, despite the already existing infection [22].

The e-ANC provides information on the current condition of pregnant women, and the midwives are able to provide preventive treatment more quickly. For example, dizziness/headache reported before the intervention was at $45.6 \%$, and this has reduced to $6.7 \%$ afterward (Table 5). This is possibly due to the regular checks for body temperature, blood pressure from the beginning, facilitating the early protection against patients with COVID-19 symptoms. Therefore, the use of e-ANC is highly needed. It also plays an important role in reducing reproductive health problems. This also serves as the main supporting tool to anticipate an increase in postnatal pregnancy deaths, due to the minimal contact with health workers. In addition, antenatal care reduces maternal mortality rate during social distancing [1], [24]. This finding is a novelty to complement the research of Haddad et al., Feroz et al. [7], [8], where the comprehensive use of technology in ANC improved the reproductive health of pregnant women. Furthermore, reduced maternal mortality rate was reported during the pandemic lockdown period, especially in the Central Sulawesi Province of Indonesia. 
This study showed no positive cases of COVID-19 for pregnant women and babies born. However, miscarriages and fetal deaths were reported. A convincing relationship was not established between COVID-19 infection and the risk of miscarriage and fetal death in the second trimester. This trend is in line with Infections, Reproduction, Obstetrics, Ginecology and Recommendations in Pregnant Women-Childbirth [24], where no clear data were observed to correlate high fever with disability and fetal death.

\section{Conclusion}

The lockdown period during the COVID-19 pandemic led to a low ANC visitation rate for pregnant women. Therefore, e-ANC was introduced as an alternative solution to increase ANC (i.e., counseling, high-risk early detection, monitoring $\mathrm{Hb}$, and provision of Tablet Fe). After the implementation of the application, counseling on maternal-child health and COVID-19, and high-risk early detection were identified as the highest domain in the services provided. Furthermore, e-ANC influenced the decline in the overall reproductive health problems.

\section{Authors' Contributions}

Rosmala Nur (conceptualizing and designing the study, preparing the manuscript draft, doing revisions, or providing critique); St. Radiah (sectional scientific management), Ulfa (analyzing and interpreting the data); Rahma Dwi larasati (analyzing and interpreting the data); Nurhaya S. Patui (analyzing and interpreting the data); Elvaria Mantao (analyzing and interpreting the data); Syaiful Hendra (sectional scientific management); Hajra Rasmita Ngemba (data analysis and interpretation); Muh. Rusydi, H (sectional scientific management); and Nenita P. Domingo (sectional scientific management).

\section{Significance Statement}

This study identified the effect of COVID-19 lockdown on the low ANC visit of pregnant women. In addition, electronic antenatal care (e-ANC) for midwives and pregnant women is an alternative solution to improve care, due to increased participation in counseling, early detection of high risk, as well as
$\mathrm{Hb}$ and Fe tablet monitoring. This practice also reduces reproductive health problems.

\section{References}

1. Ministry of Health of the Republic of Indonesia. Guidelines for Pregnant Women, Postpartum Mothers and Newborn Babies during Social Distancing. Healthy Movement of Life. Ministry of Health of the Republic of Indonesia; 2020. p. 1-21.

2. Roy D, Tripathy S, Kumar S, Sharma N, Kumar S, Kaushal V. Study of knowledge, attitude, anxiety and perceived mental healthcare need in Indian population during COVID-19 pandemic. Asian J Psychiatr. 2020;51(1):102083. https://doi. org/10.1016/j.ajp.2020.102083

PMid:32283510

3. Rasmussen SA, Smulian JC, Lednicky JA, Wen TS, Jamieson DJ. Coronavirus Disease 2019 (COVID-19) and Pregnancy: What obstetricians need to know. Am J Obstet Gynecol. 2020;222(5):415-26. https://doi.org/10.1016/j. ajog.2020.02.017

PMid:32105680

4. Nur R, Fitrasyah SI, Mallongi A. Women's reactions and health disorders caused by abuse during the pregnancy-postpartum period. Med Legal Update. 2020;20(1):1329-34.

5. Liu D, Li L, Zheng D, Wang J, Yang L, Zheng C, et al. Pregnancy and perinatal outcomes of women with coronavirus disease (COVID-19) pneumonia: A preliminary analysis. AJR Am J Roentgenol. 2020;215(1):127-32. https://doi.org/10.2139/ ssrn.3548758

PMid:32186894

6. Mamar S, Puspasari I, Demak K, Elli BY, Rusydi M, Erina RT Mother's behavior in pregnancy-puerperal treatments and reproductive health disorders. Med Legal Update. 2020;20(1):1341-6.

7. Haddad SM, Souza RT, Cecatti JG. Mobile technology in health (mHealth) and antenatal care searching for apps and available solutions: A systematic review. Int J Med Inform. 2019;127(1):127. https://doi.org/10.1016/j.jimedinf.2019.04.008

8. Feroz A, Perveen S, Aftab W. Role of mHealth applications for improving antenatal and postnatal care in low and middle income countries: A systematic review. 2017;17(1):704. https:// doi.org/10.1186/s12913-017-2664-7

PMid:29115992

9. Schwartz DA. An analysis of 38 pregnant women with COVID-19, their newborn infants, and maternal-fetal transmission of SARS-CoV-2 : Maternal coronavirus infections and pregnancy outcome. Arch Patholody Lab Med. 2020;1:1-25. https://doi. org/10.5858/arpa.2020-0901-sa

10. Daw MA. Preliminary epidemiological analysis of suspected cases of coronavirus infection in Libya. Travel Med Infect Dis. 2020;35:101634

PMid:32205266

11. Huang C, Wang Y, Li X, Ren L, Zhao J, Hu Y, et al. Clinical features of patients infected with 2019 novel coronavirus in Wuhan, China. Lancet. 2020;6736(20):1-10.

12. Khan S, Jun L, Siddique R, Li Y, Han G, Xue M, et al. Association of COVID-19 with pregnancy outcomes in health-care workers and general women. 2020;26(6):788-90.

PMid:32278081

13. Cheng Z, Lu Y. Clinical features and chest CT manifestations of coronavirus disease 2019 (COVID-19) in a single-center study 
in Shanghai, China. 2020;215(1):121-6. PMid:32174128

14. Segars J, Katler Q, Mcqueen DB, Glenn T, Knight Z, Feinberg EC, et al. Prior and novel coronaviruses, COVID-19, and human reproduction: What is known? Fertil Steril. 2020;113(6):1140-9. https://doi.org/10.1016/j.fertnstert.2020.04.025

15. Breslin N, Baptiste C, Miller R, Fuchs K, Goffman D, Gyamfibannerman $\mathrm{C}$, et al. COVID-19 in pregnancy: Early lessons. Am J Obstet Gynecol MFM. 2020;2(2):100111. https://doi. org/10.1016/j.ajogmf.2020.100111

PMid:32518902

16. Stephen G, Mgongo M, Hashim TH, Katanga J, Stray-pedersen B, Msuya SE. Anaemia in pregnancy: Prevalence, risk factors, and adverse perinatal outcomes in Northern Tanzania. Anemia. 2018;2018:1846280. https://doi.org/10.1155/2018/1846280

PMid:29854446

17. Kedokteran F, Lampung U. Wellness and Healthy Magazine; 2020. p. 187-92.

18. Lamsihar H, Manurita RR. Socio-Demography Factors and Sosio-Psychology that Related to Anemia of Expectant Mother in Tanjung Balai City, North Sumatra Province 2006. Medan:
Health Department of North Sumatra; 2006.

19. Yang $P$, Liu P, Li D, Zhao D. Coronavirus coronavirus disease 2019, a growing threat to children? J Infect. 2020;80(6):671-93. PMid:32142929

20. Lim LM, Li S, Biswas A, Choolani M. Special report and pregnancy. Am J Obstet Gynecol. 2020;2019:521-31.

21. Zhao WZ. Relation between chest $C T$ findings and clinical conditions of coronavirus disease (COVID-19) pneumonia: A multicenter study. AJR Am J Roentgenol. 2020;214(5):1072-7. PMid:32125873

22. Firdiiansyah. Stigma Berkonstribusi Terhadap Tingginya Angka Kematian Covid-19. Jakarta; 2020. Available from: https://www. bnpb.go.id/berita/kemenkes-stigma-berkontribusi-terhadaptingginya-angka-kematian-covid19. [Last accessed on 2020 May 08].

23. Saleh SA. Coronavirus disease 2019 (COVID-19): A systematic review of imaging findings in 919 patients. 2020;215(1):87-93. PMid:32174129

24. Infections, Reproduction, Obstetrics, Ginecology and Recommendations in Pregnant Women-Childbirth. Obstetrics and Gynecology Guidelines; 2020. 